\title{
MAPEAMENTO DAS ÁREAS DE PRESERVAÇÃO PERMANENTE E DOS FRAGMENTOS FLORESTAIS NATURAIS COMO SUBSIDIO À AVERBAÇÃO DE RESERVA LEGAL EM IMÓVEIS RURAIS
}

\author{
Vicente Paulo Soares ${ }^{1}$, Adelson de Azevedo Moreira ${ }^{2}$, Carlos Antonio Alvares Soares Ribeiro ${ }^{3}$, \\ José Marinaldo Gleriani ${ }^{4}$
}

(recebido: 12 de março de 2010; aceito: 22 de agosto de 2011)

\begin{abstract}
RESUMO: Conduziu-se este trabalho, com o objetivo principal de identificar e quantificar os fragmentos florestais aptos para averbação como reserva legal, nos imóveis rurais da bacia hidrográfica do ribeirão São Bartolomeu, município de Viçosa, MG. Os procedimentos metodológicos incluíram: 1) o mapeamento de 78 fragmentos florestais mediante interpretação visual de uma imagem Ikonos II ortorretificada; 2) a delimitação das Áreas de Preservação Permanente a partir de um modelo digital de elevação hidrograficamente condicionado e 3) o mapeamento de 292 imóveis rurais por meio de entrevistas com os proprietários, utilizando uma imagem do sensor Ikonos no formato analógico. Em seguida, efetuaram-se cruzamentos dos mapas gerados, permitindo a identificação dos fragmentos passíveis de serem averbados como reserva legal do imóvel. Os resultados indicaram que, do total de imóveis avaliados, apenas 41 (14,04\%) possuem acima de $20 \%$ de cobertura florestal, estando aptos a atenderem a legislação ambiental no que se refere à reserva legal.
\end{abstract}

Palavras-chave: Área de preservação permanente, imagem Ikonos II, fragmento florestal, SIG.

\section{MAPPING PERMANENT PRESERVATION AREAS AND NATURAL FOREST FRAGMENTS AS SUBSIDY TO THE REGISTRATION OF LEGAL RESERVE AREAS IN RURAL PROPERTIES}

\begin{abstract}
The major objective of this work was to identify and quantify forest fragments suitable to be used as private protected land in rural properties located in the São Bartolomeu creek watershed, State of Minas Gerais, Brazil. The methodological procedures included: mapping of 78 forest fragments through the visual interpretation of an Ikonos II satellite image; delineation of Permanent Preservation Areas (PPAs) from a hydrographically conditioned digital elevation model and mapping of 292 rural properties through interviews with owners, with the aid of a printed Ikonos II image. The generated maps were overlapped (crossed), allowing the identification of forest fragments that could be used as private protected land in rural property. The result indicated that, from the total of properties evaluated, only 41 (14.04\%) have more than 20\% of forest cover, and therefore, are in condition to attend the environmental law for private protected land.
\end{abstract}

Key words: Permanent preservation area, Ikonos II image, forest fragment, GIS.

\section{INTRODUÇÃO}

A expansão da fronteira agrícola, com a retirada da vegetação nativa ou a substituição por outro tipo de uso da terra, tem agravado o processo da fragmentação florestal e provocado consequências negativas nos diferentes compartimentos da natureza, afetando inúmeras espécies da fauna e da flora. A Floresta Atlântica é um dos biomas que tem sofrido grande impacto, mas, mesmo assim, continua sendo responsável por garantir serviços ambientais essenciais à vida humana e à qualidade de vida das pessoas que nele vivem.

Sendo assim, o uso inadequado das terras é uma questão relevante, uma vez que boa parte das propriedades rurais apresenta algum conflito legal de uso da terra. Os dois instrumentos legais mais importantes para disciplinar o uso da terra são: o Código Florestal Brasileiro, instituído pela Lei Federal no 4.771, de 15 de setembro de 1965 (BRASIL, 1965) que, nos seus artigos $2^{\circ}$ e $3^{\circ}$, trata das áreas de preservação permanente e, em

${ }^{1}$ Engenheiro Florestal, Professor Dr. em Ciências Florestais - Departamento de Engenharia Florestal - Universidade Federal de Viçosa/UFV 36.570-000 - Viçosa, MG - vicente@ufv.br

${ }^{2}$ Engenheiro Agrimensor, Professor Dr. em Ciência Florestal - Instituto Federal de Educação - Campus de Vitória - 29040-780 - Vitória, ES adelsonmoreira@gmail.com

${ }^{3}$ Engenheiro Agrícola, Professor Dr. em Ciências Florestais - Departamento de Engenharia Florestal - Universidade Federal de Viçosa/UFV 36.570-000 - Viçosa, MG - cribeiro@ufv.br

${ }^{4}$ Engenheiro Agrônomo, Professor Dr. em Sensoriamento Remoto - Departamento de Engenharia Florestal - Universidade Federal de Viçosa/UFV 36.570-000 - Viçosa, MG - gleriani@ufv.br

Cerne, Lavras, v. 17, n. 4, p. 555-561, out./dez. 2011 
particular, a Lei no 14.309 de 19 de maio de 2002, do Estado de Minas Gerais, que dispõe sobre as políticas florestais naquele estado.

Além de instituir as APPs, a legislação também estabeleceu as restrições de uso para as florestas de domínio privado que não se encaixam nas condições de APPs, as chamadas Reservas Legais (RL). As RLs são áreas de cobertura arbóreas, localizadas dentro do imóvel, onde não é permitido o corte raso.

Aárea destinada à RL depende da região geográfica do país e do bioma em que se insere a propriedade florestal em questão, devendo ser averbada no Registro de Imóveis para conhecimento de terceiros. A sua não averbação, no entanto, não exonera o proprietário da obrigação de respeitá-la, pois ela não se constitui pela averbação, que é um simples registro que declara a existência da Reserva Legal (ANTUNES, 2005).

O percentual mínimo da RL na Amazônia Legal é de $80 \%$, enquanto que, para os cerrados dessa região, é de $35 \%$. Nas outras regiões do país, o percentual é de no mínimo $20 \%$ para as outras formações vegetais, incluindo cerrados e floresta Atlântica (BRASIL, 1965).

A averbação da área de RL à margem da matrícula significa que essa área ficará registrada na matrícula do imóvel no Cartório de Registro de Imóveis; sempre que houver algum processo de venda, troca ou outros, a área de RL aparecerá nos documentos do referido imóvel (GRIPP JÚNIOR, 2009).

A Lei no ${ }^{8.171}$, de 17 de janeiro de 1991, dispõe sobre política agrícola e estatui, em seu art. 104, que serão isentas de tributação e do pagamento do Imposto Territorial Rural, as áreas dos imóveis rurais consideradas de RL e APP. Essa mesma Lei estabelece a obrigatoriedade de recomposição da reserva florestal legal das propriedades e assentamentos rurais.

A averbação da RLé importante para o planejamento de uso da terra e de manejo de ecossistemas em nível local. O poder público pode orientar os proprietários rurais na formação de corredores ecológicos entre Unidades de Conservação ou no estabelecimento de zonas-tampão (zonas de amortecimento) nos arredores das Unidades, garantindo, assim, a conservação de maiores extensões de terra cobertas com a vegetação nativa (BITTENCOURT; MENDONÇA, 2004).

Nos últimos anos, as tecnologias de sensoriamento remoto (SR) e de sistemas de informações geográficas (SIG) têm sido amplamente utilizadas na discriminação, no mapeamento e no monitoramento dos recursos naturais terrestres. Os dados obtidos por satélites são obtidos de forma repetitiva, em intervalos relativamente curtos. Esses dados podem ser processados rapidamente, para a geração de mapas temáticos da superfície terrestre.

Diante do exposto, neste trabalho, objetivou-se identificar e quantificar os fragmentos florestais aptos a compor a reserva legal nos imóveis rurais.da bacia hidrográfica do ribeirão São Bartolomeu, município de Viçosa, mediante a combinação de tecnologias de sensoriamento remoto e de sistemas de informações geográficas.

\section{MATERIAL E MÉTODOS}

\subsection{Localização e característica da área de estudo}

A área de estudo situa-se no município de Viçosa, Zona da Mata Mineira, estando compreendida entre as coordenadas geográficas $20^{\circ} 44^{\prime}$ e $20^{\circ} 51^{\prime}$ de latitude Sul e $42^{\circ} 50^{\prime} \mathrm{e} 42^{\circ} 55^{\prime}$ de longitude Oeste. Essa área de 2.826,83 ha compreende parte da bacia do ribeirão São Bartolomeu, ilustrada na Figura 1.

A região caracteriza-se por uma topografia fortemente acidentada, apresentando porções reduzidas de área plana. Apresenta uma altitude média de $649 \mathrm{~m}$, encontrando-se altitudes superiores a $800 \mathrm{~m}$ nos topos dos muitos morros do município. Os fundos de seus vales correspondem ao leito maior, periodicamente inundável, seguido de terraços assimétricos, preferidos para a agricultura e habitações. As vertentes desenvolvemse seguindo uma linha côncava-convexa-topo e parte íngreme, com escassos remanescentes florestais nativos, caracterizadas por minifúndios com mão de obra essencialmente familiar, onde praticam-se a agricultura e a pecuária de subsistência (REZENDE, 1971).

\subsection{Materiais e aplicativos utilizados}

Para a consecução desse trabalho utilizou-se uma ortoimagem do satélite Ikonos II, fusionada colorida com resolução espacial de $1 \mathrm{~m}$ e já disponibilizada no sistema de projeção UTM, zona 23S, datum SAD-69; um modelo digital de elevação com padrão de exatidão cartográfica (PEC) classe A para a escala 1:10.000 (SANTOS, 2008), com curvas de nível com equidistância vertical de $5 \mathrm{~m}$; cartas topográficas digitais do IBGE na escala 1/50.000, e os aplicativos ArcGis 9.3, Erdas Imagine 9.2 e Anudem 5.2 . 

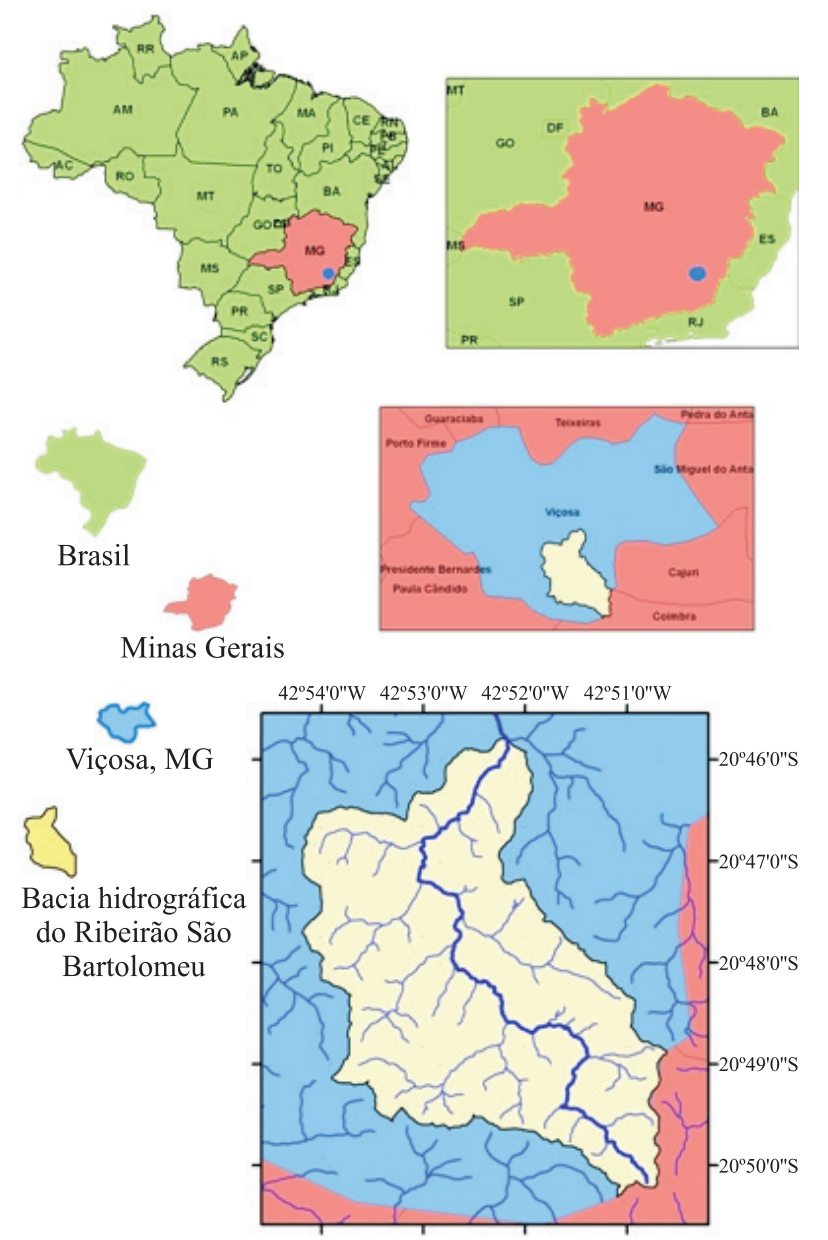

Figura 1 - Localização da área de estudo, destacando-se o ribeirão São Bartolomeu.

Figure 1 -Study area location, emphasizing the São Bartolomeu creek.

\subsection{Procedimentos metodológicos}

2.3.1. Desenvolvimento do Modelo Digital de Elevação Hidrograficamente Condicionado (MDEHC)

A geração do MDEHC usou a malha hidrográfica durante o processo de interpolação dos dados de altimetria, para melhorar a definição do relevo ao longo das calhas dos rios. Para tanto, houve que se assegurar a conectividade de todos os arcos da hidrografia e a sua correta orientação no sentido do escoamento. A criação do MDEHC foi realizada utilizando o aplicativo Anudem versão 5.2, estipulando o valor de $1 \mathrm{~m}$ para a sua resolução geométrica. Em seguida, efetuou-se o refinamento do modelo resultante, segundo a metodologia de Ribeiro et al. (2005). A delimitação da área de drenagem da bacia hidrográfica do ribeirão São Bartolomeu foi feita com o comando watershed do módulo Spatial Analyst do ArcGis que requer, como dados de entrada, a grade de direções de escoamento e o ponto associado à foz da bacia. O limite da bacia, assim obtido, foi então utilizado para recortar os dados originais.

2.3.2 Delimitação das Áreas de Preservação Permanente (APPs) com base na Resolução no 303 CONAMA

Foi adotada a metodologia desenvolvida por Ribeiro et al. (2002, 2005), para a delimitação automática das áreas de preservação permanente, implementada, tomando por base o modelo digital de elevação hidrograficamente condicionado. Seguindo-se as especificações constantes dos art. 2ㅇ e 3을 da Resolução no 303/2002 do CONAMA, foram delimitadas as categorias de APPs situadas no terço superior dos morros, nas encostas com declividades superiores a $45^{\circ}$, nas nascentes e suas respectivas áreas de contribuição, nas zonas ripárias e nos terços superiores das sub-bacias.

\subsubsection{Mapeamento dos fragmentos florestais}

Foi realizada a interpretação visual da ortoimagem do satélite Ikonos II, quando foram delimitados 78 fragmentos florestais representando os diferentes estágios de sucessão da vegetação natural. Efetuaram-se visitas a campo para validação dos resultados da interpretação visual.

\subsubsection{Delimitação das divisas dos imóveis rurais}

$\mathrm{Na}$ ortoimagem Ikonos II impressa, foram delimitadas as linhas divisórias de 292 imóveis por meio de entrevista com os proprietários em seus respectivos imóveis. Em seguida, com o uso do ArcGis, aplicando o módulo de edição do ArcMap e com a imagem digital e analógica, foi efetuada a devida correção das linhas divisórias, observando cercas, valos, estradas, cursos d'água, divisores e as anotações das informações dos moradores, gerando-se, assim, o mapa dos imóveis.

\subsubsection{Identificação de fragmentos aptos para reserva legal}

A análise dos dados oriundos do mapa de fragmentos florestais com o cruzamento do mapa de APPs da bacia, por meio do ArcMap do ArcGis, resultou num mapa de fragmentos florestais fora das áreas de preservação permanentes, aptos a servirem de reserva legal. Desse resultado, juntamente com o mapa de imóveis, foram identificados os fragmentos passíveis de serem averbados como reserva legal do imóvel.

Cerne, Lavras, v. 17, n. 4, p. 555-561, out./dez. 2011 


\section{RESULTADOS E DISCUSSÃO}

\subsection{Delimitação e quantificação das áreas de preservação permanente}

Foram delimitadas, automaticamente, todas as categorias de APPs diretamente vinculadas ao elementos definidores de uma bacia hidrográfica: situadas no terço superior dos morros, nas encostas com declividades superior a $45^{\circ}$, nas nascentes e suas respectivas áreas de contribuição, ao longo das zonas ripárias e ao longo dos divisores d'água, no terço superior das sub-bacias. $\mathrm{Na}$ Figura 2, ilustra-se a distribuição espacial de todas as categorias de APPs presentes na área de estudo.

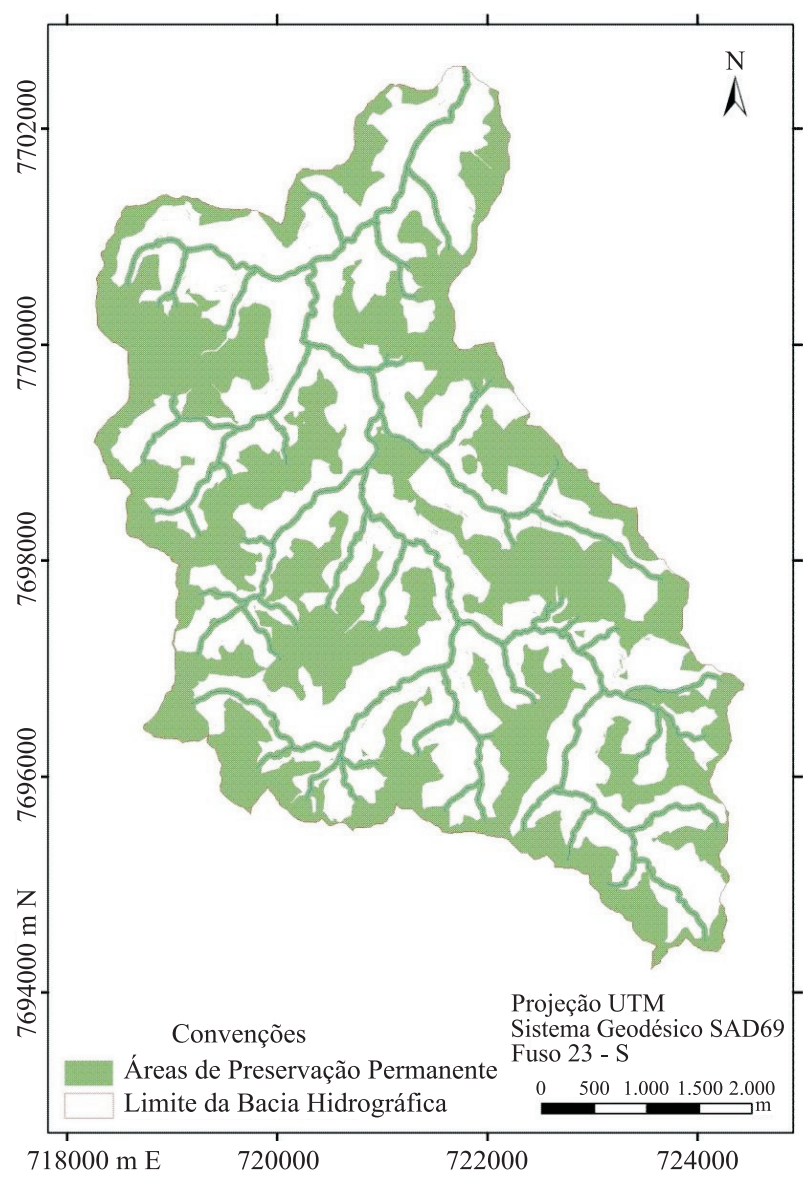

Figura 2 - Mapa com todas as categorias de Áreas de Preservação Permanentes da bacia do ribeirão São Bartolomeu, Minas Gerais.

Figure 2-Map showing the categories of Permanent Preservation Areas in the São Bartolomeu creek watershed, State of Minas Gerais, Brazil.
Na Tabela 1, constata-se a quantificação das APPs na área de estudo. Nota-se que a categoria terço superior das sub-bacias, com 1.037,32 ha (67,77\%) foi a de maior participação entre as categorias de APPs. Tal comportamento ocorreu também nos trabalhos realizados por Oliveira (2002), no município de Viçosa - MG; Oliveira et al. (2008), nos municípios de Alto Jequitibá, Alto Caparaó, Caparaó e Espera Feliz - MG; e Nascimento et al. (2005), no município de Alegre - ES. Nota-se, ainda, que as APPs ocuparam uma área de 1.530,67 ha, de um total de 2.826,83 ha da área de estudo, representando $54,15 \%$ de áreas legalmente protegidas.

Tabela 1 - Quantificação das Áreas de Preservação Permanente (APPs) na bacia do ribeirão São Bartolomeu, Minas Gerais.

Table 1 -Quantification of Permanent Preservation Areas in the São Bartolomeu creek watershed, State of Minas Gerais, Brazil.

\begin{tabular}{lcc}
\hline Categorias de APPs & Área (ha) & $\%$ \\
\hline Topos de morro & 27,96 & 1,83 \\
$\begin{array}{l}\text { Encostas com declividade } \\
\text { superior a } 45^{\circ}\end{array}$ & 5,51 & 0,36 \\
$\begin{array}{l}\text { Nascentes e suas áreas de } \\
\text { contribuição }\end{array}$ & 436,06 & 28,49 \\
Zonas ripárias & 325,96 & 21,30 \\
Terço superior das sub-bacias & $1.037,32$ & 67,77 \\
Total de APPs & $1.530,67$ & 54,15 \\
Área total da bacia & $2.826,83$ & 100 \\
\hline
\end{tabular}

\subsection{Mapeamento dos imóveis rurais}

A ortoimagem IKONOS II e os levantamentos de campo baseados em entrevista com os proprietários, com a verificação das divisas dos imóveis, observando as cercas, valos, estradas, cursos d'água, divisores etc., permitiram identificar e mapear 292 imóveis na área de estudo, conforme ilustra a Figura 3. Nota-se, pela figura, que os fragmentos apresentam-se com diferentes tamanhos e formas bastante irregulares.

Analisando a Tabela 2, verifica-se que $38,36 \%$ dos imóveis da bacia são menores que 3 ha e $90,41 \%$ estão abaixo de 24 ha, indicando que a maioria é de pequenas propriedades. Apenas cinco imóveis possuem áreas entre 63 e 213 ha. Essa é uma realidade que ocorre na grande maioria dos municípios da Zona da Mata Mineira, com predomínio do pequeno produtor que pratica a agricultura de subsistência, em geral dentro das APPs, descumprindo a legislação florestal vigente. 


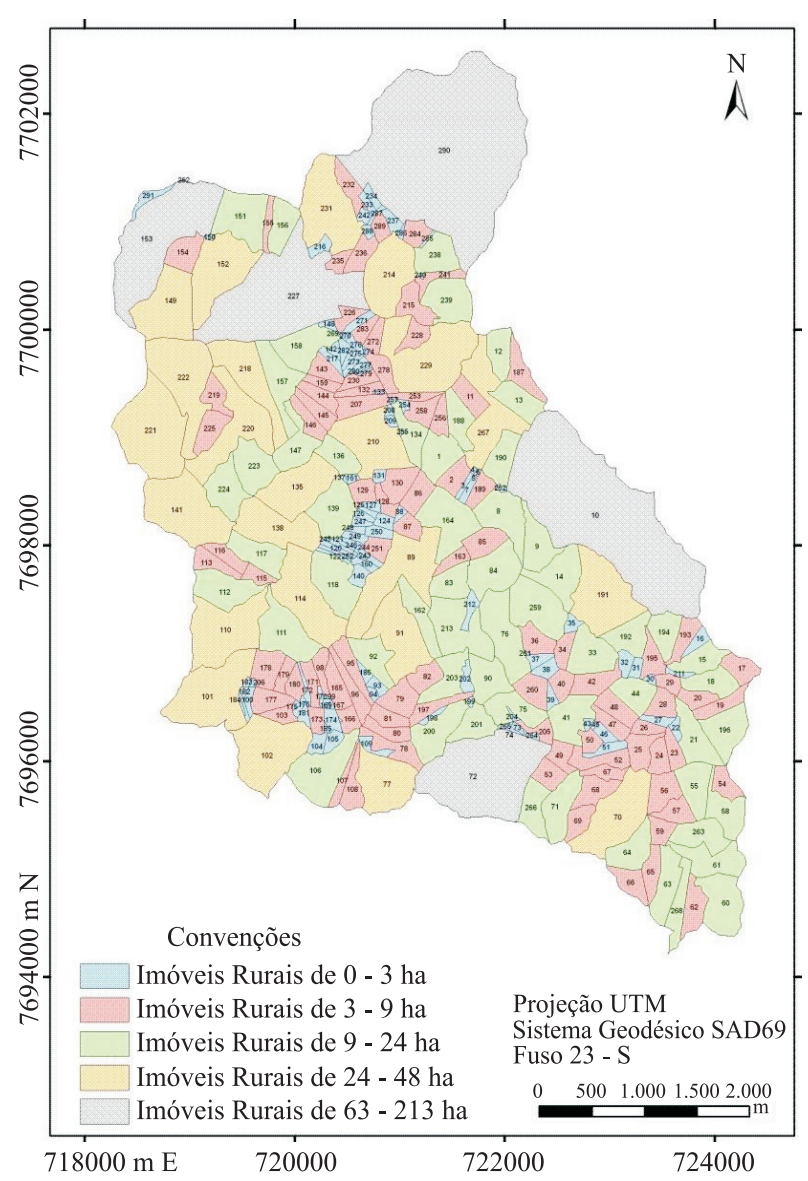

Figura 3 - Localização dos imóveis rurais na bacia hidrográfica do ribeirão São Bartolomeu, município de Viçosa, Minas Gerais.

Figure 3 - Location of rural properties in the São Bartolomeu creek watershed, State of Minas Gerais, Brazil.

Tabela 2 - Quantificação dos imóveis rurais por classes de áreas (ha) e frequências na bacia hidrográfica do ribeirão São Bartolomeu, Minas Gerais.

Table 2-Quantification of rural properties by area classes (ha) and frequencies in the São Bartolomeu creek watershed, State of Minas Gerais, Brazil.

\begin{tabular}{lcccc}
\hline \multirow{2}{*}{ Classe de área } & \multicolumn{2}{c}{ Imóveis } & \multicolumn{2}{c}{ Área } \\
\cline { 2 - 5 } & Número & $\%$ & ha & $\%$ \\
\hline Imóveis rurais de 0 - 3 ha & 112 & 38,36 & 132,16 & 4,68 \\
Imóveis rurais de 3 - 9 ha & 95 & 32,53 & 537,84 & 19,03 \\
Imóveis rurais de 9 - 24 ha & 57 & 19,52 & 800,22 & 28,31 \\
Imóveis rurais de 24 - 48 ha & 23 & 7,88 & 756,45 & 26,76 \\
Imóveis rurais de 63 - 213 ha & 5 & 1,71 & 600,15 & 21,23 \\
\hline Total & 292 & 100 & 2826,83 & 100 \\
\hline
\end{tabular}

O estabelecimento dos intervalos de classe foi feito no ArcGIS, aplicando-se o método de Jenks, que maximiza o contraste entre classes e minimiza a variância intraclasse e aceitando-se o valor padrão de 5 classes.

\subsection{Averbação de reservas legais}

Segundo o Código Florestal Nacional, a averbação da reserva legal dar-se-á em uma área localizada no interior de uma propriedade ou posse rural, excetuada a de preservação permanente, necessária ao uso sustentável dos recursos naturais, à conservação e reabilitação dos processos ecológicos, à conservação da biodiversidade e ao abrigo e proteção de fauna e flora nativas (BRASIL, 1965).

A Lei nº 14.309/2002 do Estado de Minas Gerais, no $\S 1^{\circ}$ do seu artigo 16 , assim estabelece:

Respeitadas as peculiaridades locais e o uso econômico da propriedade, a reserva legal será demarcada em continuidade a outras áreas protegidas, evitando-se a fragmentação dos remanescentes da vegetação nativa e mantendo-se os corredores necessários ao abrigo e ao deslocamento da fauna silvestre (MINAS GERAIS, 2002).

$\mathrm{Na}$ Figura 4, apresenta-se o mapa contendo os 292 imóveis rurais na área de estudo, com as respectivas APPs e os fragmentos florestais que se localizam dentro das APPs, enquanto que na Figura 5, aparecem as mesmas informações da Figura 4, porém mostrando os fragmentos fora das APPs, os quais são considerados aptos para a averbação das RLs.

Na Tabela 3, apresentam-se as percentagens dos fragmentos florestais fora das APPs, a nível de imóvel rural. Pela análise dos dados contidos nessa tabela, notase que 41 imóveis $(14,04 \%)$ possuem mais de $20 \%$ dos fragmentos localizados fora de suas APPs, indicando que estes têm condições de atender à legislação referente à demarcação das áreas destinadas às Reservas Legais. Nota-se, ainda, que os 251 imóveis restantes na área de estudo não atendem à legislação, no que se refere à demarcação de reservas. Destes, 11 possuem entre 15 e $20 \%$; 19 , entre 10 e $15 \%$; e 25 possuem entre 5 e $10 \%$ de fragmentos florestais fora de APPs. Os 196 imóveis em piores condições, ou $67,12 \%$ do total, apresentam menos de $5 \%$ de cobertura florestal fora de APPs, comprometendo-os no cumprimento da legislação sobre averbação de reservas legais. Para os imóveis, cuja cobertura florestal não atende ao mínimo de $20 \%$, deve-se selecionar, preferencialmente, outra classe de cobertura vegetal para ser recomposta no futuro.

Cerne, Lavras, v. 17, n. 4, p. 555-561, out./dez. 2011 


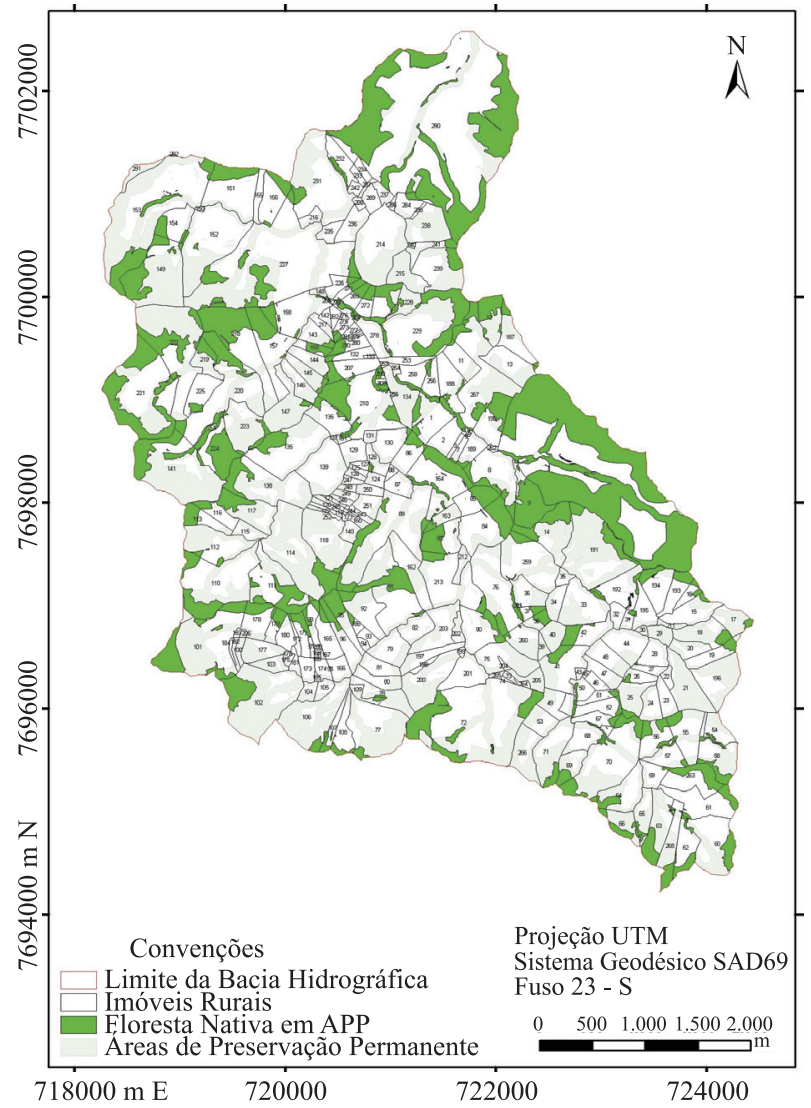

Figura 4 - Mapa dos fragmentos florestais em áreas de preservação permanente na bacia hidrográfica do ribeirão São Bartolomeu, município de Viçosa, Minas Gerais.

Figure 4 - Map of forest fragments inside Permanent Preservation Areas in the São Bartolomeu creek watershed, State of Minas Gerais, Brazil.

Tabela 3 - Percentagem de fragmentos florestais fora das APPs e número de imóveis rurais na bacia hidrográfica do ribeirão São Bartolomeu, Minas Gerais.

Table 3 - Percentage of forest fragments outside PPAs and number of rural properties in the São Bartolomeu creek watershed, State of Minas Gerais, Brazil.

\begin{tabular}{lccc}
\hline $\begin{array}{l}\text { \% de fragmentos } \\
\text { florestais fora de APPs }\end{array}$ & $\begin{array}{c}\text { Número de } \\
\text { imóveis }\end{array}$ & $\begin{array}{c}\text { \% de } \\
\text { imóveis }\end{array}$ & $\begin{array}{c}\text { Área } \\
\text { (ha) }\end{array}$ \\
\hline $0---\mid$ 5 & 196 & 67,12 & 13,11 \\
$5---\mid 10$ & 25 & 8,56 & 37,34 \\
$10--\mid$ | 15 & 19 & 6,51 & 30,10 \\
$15---\mid 20$ & 11 & 3,77 & 18,45 \\
$\geq 20$ & 41 & 14,04 & 212,37 \\
\hline Total & 292 & 100 & 311,38 \\
\hline
\end{tabular}

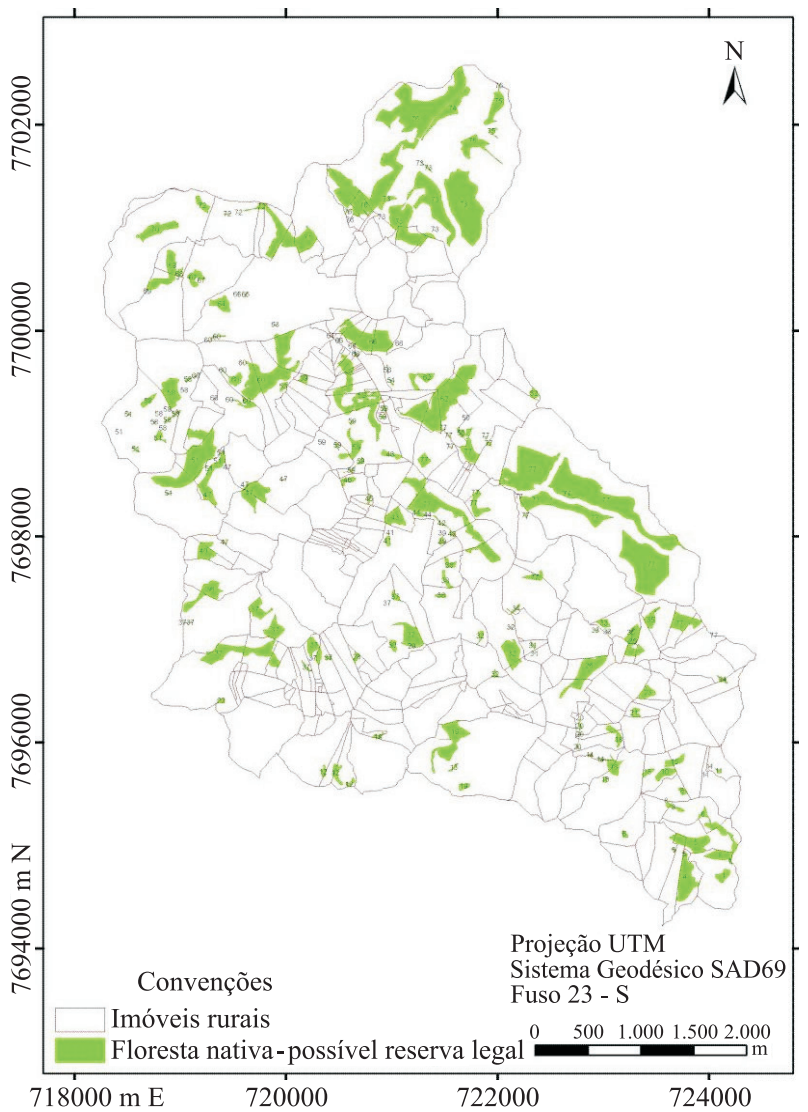

Figura 5 - Mapa dos fragmentos florestais fora das APPs, na bacia hidrográfica do ribeirão São Bartolomeu, município de Viçosa, Minas Gerais.

Figure 5 - Map of forest fragments outside Permanent Permanent Areas in the São Bartolomeu creek watershed, State of Minas Gerais, Brazil.

Gripp Júnior (2009), trabalhando numa área localizada parcialmente nos municípios de Ervália, Araponga e Canaã, no estado de Minas Gerais, constatou que, entre 151 imóveis analisados, apenas 13 atenderiam à demarcação de Reserva Legal, por possuírem mais de 20\% das coberturas florestais fora das Áreas de Preservação Permanente.

Deve-se ressaltar que, no capítulo 15 da Lei $\mathrm{n}^{\circ}$ 14.309/2002 do Estado de Minas Gerais, há um atenuante no que se refere ao percentual da Reserva Legal na propriedade, em que é levado em conta o tamanho do imóvel: "Na propriedade rural destinada à produção, será admitido pelo órgão ambiental competente o cômputo das áreas de vegetação nativa existentes em áreas de preservação permanente no cálculo do percentual de

Cerne, Lavras, v. 17, n. 4, p. 555-561, out./dez. 2011 
reserva legal, desde que não implique conversão de novas áreas para o uso alternativo do solo, e quando a soma da vegetação nativa em área de preservação permanente e reserva legal exceder a:

I - $50 \%$ da propriedade rural com área superior a 50 ha, quando localizado no Polígono das Secas, e igual ou superior a 30 ha, nas demais regiões do Estado.

II $-25 \%$ da propriedade rural com área igual ou inferior a 50 ha, quando localizada no Polígono das Secas, e igual ou inferior a 30 ha, nas demais regiões do Estado".

Porém, a área de estudo não se encontra localizada no Polígono das Secas. Assim, em todos os imóveis acima de 30 ha mapeados, o cômputo das áreas de vegetação nativa existentes em áreas de preservação permanente no cálculo do percentual de reserva legal não atingiu os 50\% estabelecidos pela legislação.

\section{CONCLUSÕES}

A delimitação automática das áreas de preservação permanente foi imprescindível para a definição de áreas de Reservas Legais.

As áreas de preservação permanente mapeadas ocupam $54,15 \%$ da bacia hidrográfica estudada, mostrando o impacto da legislação ambiental florestal vigente em regiões de topografia acidentada.

Dos 78 fragmentos florestais mapeados na bacia do ribeirão São Bartolomeu, aproximadamente $80 \%$ apresentaram áreas inferiores a 10 ha, indicando um alto grau de degradação de sua cobertura florestal.

Dos 292 imóveis rurais na área de estudo, apenas $41(14,04 \%)$ possuem cobertura florestal em condições de atender a legislação ambiental referente à demarcação de reservas legais.

\section{REFERÊNCIAS}

ANTUNES, P. B. Direito ambiental. 8. ed. Rio de Janeiro: Lúmen Júris, 2005. 940 p.

BITTENCOURT, M. D.; MENDONÇA, R. R. Viabilidade de conservação dos remanescentes de cerrado no Estado de São Paulo. São Paulo: Annablume; FAPESP, 2004. 170 p.

BRASIL. Lei no $\mathbf{- 1 . 7 7 1}$, de 15 de setembro de 1965. Institui o novo Código Florestal. Brasília, 15 set. 1965.

GRIPP JÚNIOR, J. A ortorretificação de imagens de alta resolução para aplicação em estudo do cadastro técnico rural e mapeamento de áreas de preservação permanente e reservas legais. 2009. 152 p. Tese (Doutorado em Ciência Florestal) - Universidade Federal de Viçosa, Viçosa, 2009.

MINAS GERAIS. Lei n- $\mathbf{1 4 . 3 0 9}$, de 19 de junho de 2002. Dispõe sobre as políticas florestais e de proteção à biodiversidade no Estado. Belo Horizonte, 2002. Disponível em: <http://www.siam.mg.gov.br/sla/download $>$. Acesso em: 5 ago. 2009.

NASCIMENTO, M. C.; SOARES, V. P.; RIBEIRO, C. A. A. S.; SILVA, E. Uso do geoprocessamento na identificação de conflito de uso da terra em áreas de preservação permanente na bacia do rio Alegre, Espírito Santo. Ciência Florestal, Santa Maria, v. 15, n. 2, p. 207-220, 2005.

OLIVEIRA, F. S.; SOARES, V. P.; PEZZOPANE, J. E. M.; GLERIANI, J. M.; LIMA, G. S.; SILVA, E.; RIBEIRO, C. A. A. S.; OLIVEIRA, A. M. S. Identificação de conflito de uso da terra em Áreas de Preservação Permanente no entorno do parque nacional do Caparaó, Estado de Minas Gerais. Revista Árvore, Viçosa, v. 32, n. 5, p. 899-908, 2008.

OLIVEIRA, M. J. Uma proposta metodológica para a delimitação automática de áreas de preservação permanente em topos de morro e em linhas de cumeada. 2002. Dissertação (Mestrado em Ciências Florestais) Universidade Federal de Viçosa, Viçosa, 2002.

REZENDE, S. B. Estudo de crono-toposequência em Viçosa, Minas Gerais. 1971. 71 f. Dissertação (Mestrado em Fitotecnia) - Universidade Federal de Viçosa, Viçosa, 1971.

RIBEIRO, C. A. A. S.; OLIVEIRA, M. J.; SOARES, V. P.; PINTO, F. A. C. Delimitação automática de áreas de preservação permanente em topos de morro e em linhas de cumeada: metodologia e estudo de caso. In: SEMINÁRIO DE ATUALIZAÇÃO EM SENSORIAMENTO REMOTO E SISTEMAS DE INFORMAÇÕES GEOGRÁFICAS APLICADOS À ENGENHARIA FLORESTAL, 5., 2002, Curitiba. Anais... Curitiba: FUPEF, 2002. CD-ROM.

RIBEIRO, C. A. A. S.; SOARES, V. P.; OLIVEIRA, A. M. S.; GLERIANI, J. M. O desafio da delimitação de áreas de preservação permanente. Revista Árvore, Viçosa, v. 29, n. 2 , p. 203-212, 2005.

Cerne, Lavras, v. 17, n. 4, p. 555-561, out./dez. 2011 
